\title{
Modelling the effects of fishing on the biomass of the world's oceans from 1950 to 2006
}

\author{
Laura Tremblay-Boyer ${ }^{1{ }^{*}}$, Didier Gascuel $^{2}$, Reg Watson $^{1}$, Villy Christensen ${ }^{1}$, \\ Daniel Pauly ${ }^{1}$
}

${ }^{1}$ Fisheries Centre, Aquatic Ecosystem Resource Laboratory, University of British Columbia, 2202 Main Mall, Vancouver, BC V6T 1Z4, Canada

${ }^{2}$ Université Européenne de Bretagne, UMR Agrocampus Ouest/INRA Ecologie et Santé des Ecosystèmes, 65 rue de Saint-Brieuc, CS 84215, 35042 Rennes Cedex, France

\begin{abstract}
Marine fisheries have endured for centuries but the last $50 \mathrm{yr}$ have seen a drastic increase in their reach and intensity. We generated global estimates of biomass for marine ecosystems and evaluated the effects that fisheries have had on ocean biomass since the 1950s. A simple and versatile ecosystem model was used to represent ecosystems as a function of energy fluxes through trophic levels (TLs). Using primary production, sea surface temperature, transfer efficiency, fisheries catch and TL of species, the model was applied on a half-degree spatial grid covering all oceans. Estimates of biomass by TLs were derived for marine ecosystems in an unexploited state, as well as for all decades since the 1950s. Trends in the decline of marine biomass from the unexploited state were analyzed with a special emphasis on predator species as they are highly vulnerable to overexploitation. This study highlights 3 main trends in the global effects of fishing: (1) predators are more affected than organisms at lower TLs; $(2)$ declines in ecosystem biomass are stronger along coastlines than in the High Seas; and (3) the extent of fishing and its impacts have expanded from north temperate to equatorial and southern waters in the last $50 \mathrm{yr}$. More specifically, this modelling work shows that many oceans historically exploited by humans have seen a drastic decline in their predator biomass, with approximately half of the coastal areas of the North Atlantic and North Pacific showing a decline in predator biomass of more than $90 \%$.
\end{abstract}

KEY WORDS: Ecosystem modelling $\cdot$ Fisheries $\cdot$ Marine predators $\cdot$ Energy flow $\cdot$ Trophic level

\section{INTRODUCTION}

Understanding marine systems can be challenging as we cannot observe their components directly. Models have been valuable tools to aid our comprehension of marine processes, from individual behavior such as foraging (Walters et al. 1997) to oceanwide interactions between oceanic currents, nutrients and primary producers (Gregg et al. 2003). Models are increasingly used to address applied questions, particularly in the area of fisheries management and conservation (Walters \& Martell 2004), and recent recognition that the impacts of fishing extend well beyond the targeted species has promoted new re- search into the use of ecosystem models. There is now a general acceptance, as expressed through many international agreements, of the importance of ecosystem-based management (see e.g. McLeod et al. 2005) and legal commitments by the Parties of the Convention of Biological Diversity further emphasize the need to understand the effects of fishing at the ecosystem scale (CBD 2008).

Ecosystem modelling requires strategic decisions about the scope of the model, the types of interactions to be represented and the unit of focus (e.g. species, functional group, trophic level (TL), etc.; Plagányi 2007). The challenge is to find the optimal combination of model complexity and data require- 
ments to produce results that are robust and relevant in terms of the research or policy objectives (Fulton et al. 2003). For instance, EcoTroph (Gascuel 2005, Gascuel \& Pauly 2009) is a very simple ecosystem model that focuses on TLs instead of species, allowing the user to bypass much of the complexity that results from the accounting of intricate species interactions. The model was shown to reliably track trends in biomass by TLs in a shelf ecosystem off Guinea (Gascuel et al. 2009) and it can serve as an alternative approach for detecting changes in ecosystem properties or structure.

Understanding the impact of fishing at a local scale is essential for effective resource management, but a global overview allows for the identification of important spatial and temporal patterns in how ecosystems respond to fishing (Pauly 2007). Additionally, a global perspective is a powerful tool to communicate aspects of social and economic importance that may lead to management interventions at local and global scales (Berkes et al. 2006, Hilborn 2007). Current large-scale or global understanding of fisheries impacts comes from 2 main sources. The first is the direct analysis of locally available catch and catch composition data. This approach has shown, for example, that exaggerated Chinese catch statistics caused an apparent continuous increase in global fisheries' catches, while correcting for the overreporting led to a different picture of global catches declining over the last 2 decades (Watson \& Pauly 2001). The second method is based on the metaanalysis of data originating from a representative set of systems. For instance, Baum \& Worm (2009) summarized the effects and strength of top-down cascades from a set of locations distributed over the world's oceans.

In this report we present the application of an ecosystem model for the global oceans. The model we use has a simple structure, but relies on sound ecological assumptions and is robust enough to yield realistic, large-scale trends. It is based on the EcoTroph (Gascuel \& Pauly 2009) modelling framework, and is used to generate global estimates of marine biomass by TLs, both for their unexploited state and for all decades starting from 1950.

EcoTroph represents ecosystems through 3 fundamental properties quantified by TLs: biomass, production and kinetics (or rate of biomass turnover). Production is assumed to flow from primary producers to herbivores and predators, with losses occurring between TLs because of natural factors such as nonutilized production (or non-predation mortalities) and respiration, and anthropogenic factors such as fisheries catches. Key input parameters include primary production, environmental temperature (related to the kinetics), an estimate of the transfer efficiency between TLs, and fisheries catches. EcoTroph can generate estimates of unexploited biomass by TLs from primary production estimates and empirical predictions of the turnover rate of biomass (Gascuel et al. 2008). The estimation of unexploited biomass is a particularly interesting feature given that data on the unfished state of marine ecosystems are often anecdotal, although the emerging field of historical ecology promises to compensate for this need (e.g. Jackson 2001, Lotze \& Worm 2009).

In order not to confound the spatial effects of fishing with that of climate change, we used constant values of primary production and sea surface temperature for all years (see 'Methods'). Moreover, we decided not to account for top-down effects in our analysis though EcoTroph is able to represent them (Gascuel et al. 2009). Although it is widely known that trophic cascades have occurred in a number of fished systems (e.g. the Baltic Sea, the North Atlantic and the open oceans - see, respectively, Casini et al. 2008, Frank et al. 2005, Baum \& Worm 2009), there is a lack of scientific consensus on the factors that determine their intensity for well-studied marine ecosystems (Borer et al. 2005, Gruner et al. 2008, Frank et al. 2007, Shurin et al. 2002), let alone for the world's oceans. Our results are thus focused on predators, in part to minimize the potential effect trophic cascades could have on our biomass estimates.

In summary, the primary goal of this study is to present global estimates of change in marine biomass by TLs between fished and unexploited states for the period 1950 to 2006. These estimates are compared under different scenarios of ecosystem response to fishing. We discuss spatial trends, with emphasis on biomass declines for specific areas and how they compare between predators and lower TLs. This research assesses the global trends in the effects of fishing on ecosystem biomass and, through the application of a simple model, helps to identify gaps in our understanding of ecosystem functioning at large scales.

\section{METHODS}

Estimates of unexploited and fished biomass for marine ecosystems were generated by applying the EcoTroph model to each cell of a $0.5^{\circ}$ by $0.5^{\circ}$ spatial grid covering the world's oceans. The main data inputs were marine primary production, sea surface 
temperature, transfer efficiency and fisheries catch data by TL. The results presented cover the period 1950-2006 with a temporal resolution of decades. The major assumptions of our approach are as follows: there is no dispersal of production between cells, spatial trends in the effects of fishing are unaffected by temporal trends in primary production and sea surface temperature, transfer efficiency is constant over time and space, and the biomass of predators is not affected by top-down effects (see below and 'Discussion' for more details).

\section{Model description}

A detailed description of the EcoTroph model is available in Gascuel et al. (2009). See also the supplement (available at www.int-res.com/articles/suppl /m442p169_supp.pdf).

EcoTroph uses TLs (TL, in the model abbreviated as $\tau$ ) as its fundamental metric to model ecosystems. By definition, primary producers have a TL of 1 and strict herbivores one of 2 . The TL of higher level consumers is computed as 1 plus the weighted average of the TL of their prey. This means that the TLs of all but a few animals are greater or equal to 2 (the exceptions are the hosts of photosynthetic algae, such as corals, and giant clams), with very few species - if any - having a TL above 5. A unit of biomass enters an ecosystem at $\tau=1$ through photosynthesis by primary producers and is transferred to higher TLs through predation or ontogeny (i.e. because organisms grow, and thus consume larger, often higher-TL prey). At the level of organisms, trophic transfers are characterized by abrupt jumps due to predation events. Because at any point in time a very large number of such transfers occur, the average of all TL transfers from primary producers to higher TLs can be described as a continuous process at the ecosystem level (Gascuel et al. 2008).

EcoTroph thus represents ecosystems by expressing 3 fundamental features (biomass, production and kinetics) as functions of TLs. Biomass is the amount of organic matter present at any moment at a given TL (expressed, e.g. in tonnes). The production is the biomass that passes through a TL in a year (in tonnes $\mathrm{yr}^{-1}$ ). The kinetics is the speed at which biomass moves across the food web (in TL $\mathrm{yr}^{-1}$ ). It is equivalent to the production/biomass value (P/B) in Ecopath models (Christensen \& Pauly 1992), which essentially amounts to a measure of biomass turnover by TL or the average time a unit of biomass stays at a given TL (Gascuel et al. 2008). The distribution of biomass (and of production) over the TLs of an ecosystem is called the trophic spectrum. For convenience, we divided the trophic spectrum into discrete intervals of width $\Delta \tau=0.1$ (see supplement).

EcoTroph's most important equation states that the biomass $B_{\tau}$ present under equilibrium conditions within the trophic class $[\tau, \tau+\Delta \tau]$ can be calculated as the ratio of mean production $P_{\tau}$ to mean kinetics $K_{\tau}$ for that TL (Gascuel et al. 2009), that is:

$$
B_{\tau}=P_{\tau} / K_{\tau}
$$

EcoTroph can thus be used to produce estimates of ecosystem biomass if production and kinetics by TL are known. Production by TL can be obtained from the primary production, the catch by TL and an estimate for the efficiency of energy transfer between TLs (transfer efficiency, TE). Unexploited production is obtained by setting fisheries catch at zero for all TLs. Kinetics by TL are generated from sea surface temperature based on the empirical model developed in Gascuel et al. (2008), which explains $54 \%$ of the observed variation in kinetics between ecosystems, and in which temperature is a significant term. The data, parameters and equations required to estimate biomass by TLs are summarized in Table 1 , with a more complete description available in the supplement.

\section{Application of the model at a global scale}

The EcoTroph model was applied separately to all cells of a $0.5 \times 0.5^{\circ}$ grid covering the world oceans, for a total of 179612 cells. Each of these was assumed to represent an isolated 'ecosystem' (i.e. without dispersal of production between cells), which is realistic for most species as the mean area of the cells is approximately $2000 \mathrm{~km}^{2}$. Biomass, production and kinetics under unexploited and fished states were calculated for TLs between 2 and 5 at intervals of $\Delta \tau=0.1$. For each cell, the model was initialized with $P_{1}=$ PP (tonnes $\mathrm{km}^{-2} \mathrm{yr}^{-1}$; where PP is primary production). The model was run to represent each decade between 1950 and 2006 using catch data by TL averaged by decade, which produced biomass estimates that were robust to extremes in the annual catch values and representative of the overall development of fisheries since the 1950s. We illustrate the global application of EcoTroph in Fig. 1. For convenience, cells belonging to an economic exclusive zone (EEZ), which in most cases end 200 nautical miles from the coast, are defined in this study as being 'coastal'. Note that the Arctic Ocean was not included in the 
Table 1. Overview of the input data and equations required by the EcoTroph model to generate estimates of biomass by trophic level, TL (for the unexploited state and decades between 1950 and 2006). Unexploited biomass, production and kinetics by TLs are $B_{\tau, \text { unexpl}}, P_{\tau \text {,unexpl }}$ and $K_{\tau, \text { unexpl, }}$ respectively; their fished counterparts are $B_{\tau}, P_{\tau}$ and $K_{\tau}$, respectively; catches are denoted as $Y_{\tau}$; and the rate of production loss to fishing is denoted as $\varphi_{\tau}$. For the sake of simplicity we did not include the parameter for the top-down effect in the equations shown below as it was set to zero

Description
For each cell, model initialized with:
Primary production, $P_{1}=\mathrm{PP}$
Sea surface temperature, SST
Model conditioned with:
Catch data by TL
Model parameter:
Transfer efficiency, $\mu$
For $\tau$ in $[2,5]$, with TL intervals $\Delta \tau=0.1:$
(I) Calculation of unexploited biomass:
1. $P_{\tau+\Delta \tau, \text { unexpl }}=P_{\tau, \text { unexpl }} \times$ exp $\left(-\mu_{\tau} \Delta \tau\right)$, with $P_{1}=$ PP
2. $K_{\tau, \text { unexpl }}=20.19 \times \tau^{-3.26} \times \exp (0.041 H)$, where $H=\mathrm{SST}$
3. $B_{\tau, \text { unexpl }}=P_{\tau, \text { unexpl }} / K_{\tau, \text { unexpl }}$
(II) Calculation of fished biomass:
4. $P_{\tau+\Delta \tau}=P_{\tau} \times \exp \left(-\mu_{\tau} \Delta \tau\right)-Y_{\tau} \times \exp \left(-\mu_{\tau} \Delta \tau / 2\right)$
5. $\varphi_{\tau}=(1 / \Delta \tau) \times \log \left(P_{\tau} / P_{\tau+\Delta \tau}\right)-\mu_{\tau}$
6. $K_{\tau}=K_{\tau, \text { unexpl }} /\left(1-\varphi_{\tau}\right)$
7. $B_{\tau}=P_{\tau} / K_{\tau}$
8. Repeat steps $4-7$ for all decades between 1950 and 2006

analyses that were aggregated over oceans because of incomplete coverage of PP values (due in part to the difficulties in measuring production by ice algae from satellite images) as well as concerns about the quality of the catch data for the Arctic in the latest (2006) version of the Sea Around Us Project catch database (but see Zeller et al. 2011).

Parameters and input data were as follows:

- A value of $10 \%$ was used for the transfer efficiency parameter, derived as the mean of estimates from a wide range of ecosystems (Pauly \& Christensen 1995). We assumed that TE is constant for all TLs, which largely holds empirically (Christensen \& Pauly 1993, Pauly \& Christensen 1995). Moreover, a sensitivity analysis was conducted to determine how the value of TE affected the biomass derived for each cell in terms of its absolute value and compared with that of other cells (see supplement).

- Primary production data for each cell were obtained from the Sea Around Us Project databases (www. seaaroundus.org), which were themselves derived from SeaWiFS chlorophyll data (http://oceancolor. gsfc.nasa.gov/SeaWiFS/) and photosynthetically active radiation (Bouvet et al. 2002) using a model described by Platt \& Sathyendranath (1988). Missing values (mostly in polar regions and areas with high cloud cover or aerosol loads) were interpolated from neighboring cells, as described in Lai (2004) (see map therein). Because we were primarily interested in the interaction between spatial trends in primary production and temporal trends in catch, we used one PP value (year = 1998) for all decades (see supplement), which means that for each ecosystem one set of biomass predictions for the unexploited state was produced for the period 19502006.

- Annual sea surface temperature values were obtained from the NOAA World Ocean Atlas 2001 (www.nodc.noaa.gov/OC5/), which has a resolution of $1^{\circ}$. The year 2001 was chosen arbitrarily to represent the last decade of the time period examined. The sea surface temperature values were directly superposed onto the $0.5 \times 0.5^{\circ}$ grid.

- Species-specific catch data for 1950-2006 came from the Sea Around Us Project's database of spatial catches, which also uses a $0.5 \times 0.5^{\circ}$ resolution (Watson et al. 2004). The database was built by integrating data of landed and reported catches from the FAO, ICES and other organizations, as well as reconstructed catch data for 12 countries (Watson \& Pauly 2001, Zeller et al. 2007). Each record contains (besides basic information such as water depth, latitude and longitude), the (wet) mass and species composition of the catch made in that cell by year. Because the EcoTroph model requires catch data for each TL (by trophic class of $\Delta \tau=0.1$ ), the Sea Around Us Project catch data had to be processed accordingly. Thus, in all cells, for each year, all specific catch records were mapped onto their TLs, with subsequent 'smoothing' resulting in a catchby-TL spectrum, or 'catch trophic spectrum'. The catch for each TL interval was then calculated by summing over all of the specific catch records that occurred in the same interval (see supplement). Mean decade catch trophic spectra were built by first constructing annual catch trophic spectra for each cell for all years from 1950 to 2006. The mean catch value of each TL interval was then taken over each of the 6 decades in the 1950-2006 period: the 1950s (1950-1959) to the 1990s (1990-1999), and the '2000s' (2000-2006). The decadal catch trophic spectrum (in tonnes $\mathrm{yr}^{-1} \mathrm{~km}^{-2}$ ) was assumed to be representative of the catch pattern in that cell for the decade in question.

- TL data for each species or group of species recorded as landed were obtained from the Sea 


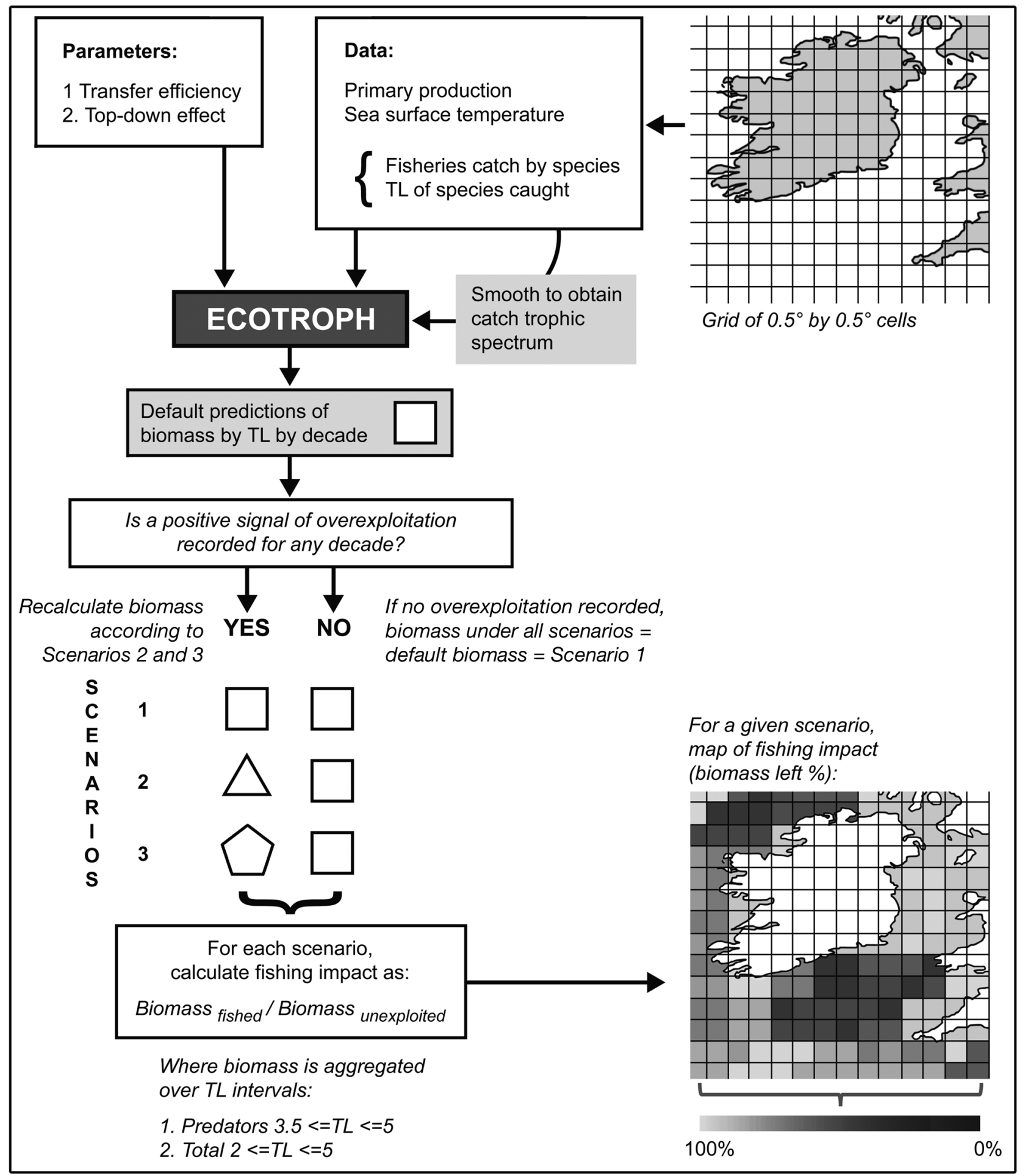

Fig. 1. Application of the EcoTroph model, using the waters around Ireland and the Celtic Sea as an example. For each cell, catch data extracted from the Sea Around Us global data sets were input into EcoTroph, which was then run to predict biomass by decade. Unexploited biomass was calculated by setting the catch at zero. By default, EcoTroph's biomass predictions correspond to Scenario 1 (square). Each cell was then tested for an overexploitation signal, which, when detected, caused the biomass of the affected trophic level (TL) to be recalculated according to Scenarios 2 (triangle) and 3 (pentagon). The percentage decline in biomass was calculated as the ratio of fished to unexploited biomass for TL intervals representing either ecosystem biomass for TL $\geq 2$ (i.e. excluding phytoplankton) or predator biomass (TL > 3.5). The resulting value corresponds to the percentage of unexploited biomass left in the system, with dark grey $=0 \%$ and light grey $=100 \%$ 
Around Us Project (see www.seaaroundus.org/topic/ species/), as derived mainly from diet composition data from FishBase (www.fishbase.org) for fishes and SeaLifeBase (www.sealifebase.org) for invertebrates. TL for each species was assumed to follow a log-normal distribution as a species might change TL between ecosystems and individuals of a population do not all feed at the same level (see supplementary material).

\section{Scenarios of ecosystem response to fishing}

In its current formulation, EcoTroph assumes by default that declining catches are caused by reduced fishing mortality (see Eqs. 2a \& 2b in the supplement); there is no mechanism of recruitment feedback between years as the 'recruitment' to the ecosystem occurs through photosynthesis by primary producers, which is itself not affected by fishing. However, declines in catch are often caused by excessive fishing mortality which reduces the biomass of exploited populations to very low levels. Instances of catch being reduced because of a decrease in fishing mortality, emphasized by Worm et al. (2009), are not as common (Mullon et al. 2005); especially in light of the continuous increase of global fishing effort (Anticamara et al. 2011).

Worldwide fisheries catches have been declining since the late 1980s once we account for catch overreporting by China (Watson \& Pauly 2001, FAO 2009). In order to account for the likely possibility that most catch declines are due to overexploitation (and not declining fishing mortality, we processed the outputs of the EcoTroph model according to a set of 3 alternative scenarios (Table 2):

- Scenario 1 (optimistic): declining catches are due to declining fishing mortality (default; see above);

- Scenario 2 (intermediate): declining catches are due to overexploitation; however, the biomass can recover after being driven down, with (generally smaller, shorter-lived) organisms at low TLs recovering faster than the (generally larger, longer-lived) organism at higher TLs;

- Scenario 3 (pessimistic): declining catches are caused by overexploitation as in Scenario 2, but biomass does not recover once it has been driven down.

Under Scenario 1, EcoTroph's estimates of biomass were deemed unbiased and therefore not changed. Under Scenarios 2 and 3, the biomass predictions generated by EcoTroph were processed post hoc for cells and decades where an overexploitation signal was detected. This signal was defined as a decline in catch (between decades) measured over a TL interval of 0.5 ( 2 additional rules were applied to account for exploitation level and temporal trends in the catch; see supplement). For these scenarios, we also assumed that if ecosystem overexploitation occurred, fishing mortality $(F)$ was the same as in the previous decade. As $Y_{\mathrm{dec}-1}=F B_{\mathrm{dec}-1}$ and $Y_{\mathrm{dec}}=F B_{\mathrm{dec}}$, then:

$$
B_{\mathrm{dec}}=B_{\mathrm{dec}-1}\left(Y_{\mathrm{dec}} / Y_{\mathrm{dec}-1}\right)
$$

which was used to re-calculate the biomass for decades with overexploitation. Lastly, the biomass predictions for Scenario 2 were further adjusted if a 'recovery signal' was detected (defined as an increase in catch for a TL interval following subsequent overexploitation; see above, Table 2 and supplement).

Table 2. Description of the 3 scenarios of ecosystem response to fishing applied to EcoTroph's default predictions of biomass by decade $\left(B_{\text {dec,default }}\right)$ as a function of catch by decade $\left(Y_{\mathrm{dec}}\right)$. The labels are used in the text to qualitatively describe the scenarios. In Scenario 2, a recovery factor $R_{\tau}$ is included to scale recovery as a function of TL, $\tau$ (see supplement)

\begin{tabular}{|c|c|c|c|}
\hline \multirow[b]{2}{*}{ Description } & \multirow{2}{*}{$\begin{array}{l}\text { Overexploitation } \\
\text { in past decade? }\end{array}$} & \multicolumn{2}{|c|}{$\begin{array}{l}\text { - Calculation of biomass } \\
\text { Overexploitation in current decade? }\end{array}$} \\
\hline & & No & Yes \\
\hline $\begin{array}{l}\text { Scenario } 1 \text { (optimistic or default): } \\
\text { catch declines because of a reduction } \\
\text { in fishing mortality; biomass is predicted } \\
\text { under levels of catch at equilibrium }\end{array}$ & $\begin{array}{l}\text { No } \\
\text { Yes }\end{array}$ & $\begin{array}{l}B_{\mathrm{dec}}=B_{\mathrm{dec}, \text { default }} \\
B_{\mathrm{dec}}=B_{\mathrm{dec}, \text { default }}\end{array}$ & $\begin{array}{l}B_{\mathrm{dec}}=B_{\mathrm{dec}, \text { default }} \\
B_{\mathrm{dec}}=B_{\mathrm{dec}, \text { default }}\end{array}$ \\
\hline $\begin{array}{l}\text { Scenario } 2 \text { (intermediate): catch declines } \\
\text { because of overexploitation; biomass is } \\
\text { allowed to recover as a function of TL if } \\
\text { overexploitation stops }\end{array}$ & $\begin{array}{l}\text { No } \\
\text { Yes }\end{array}$ & $\begin{array}{c}B_{\mathrm{dec}}=B_{\text {dec, default }} \\
B_{\mathrm{dec}}=B_{\mathrm{dec}-1}+R_{\tau}\left(B_{\mathrm{dec}, \text { default }}-B_{\mathrm{dec}-1}\right)\end{array}$ & $\begin{array}{l}B_{\mathrm{dec}}=B_{\mathrm{dec}-1}\left(Y_{\mathrm{dec}} / Y_{\mathrm{dec}-1}\right) \\
B_{\mathrm{dec}}=B_{\mathrm{dec}-1}\left(Y_{\mathrm{dec}} / Y_{\mathrm{dec}-1}\right)\end{array}$ \\
\hline $\begin{array}{l}\text { Scenario } 3 \text { (pessimistic): catch declines } \\
\text { because of overexploitation; biomass is not } \\
\text { allowed to recover if overexploitation stops }\end{array}$ & $\begin{array}{l}\text { No } \\
\text { Yes }\end{array}$ & $\begin{array}{c}B_{\mathrm{dec}}=B_{\mathrm{dec}, \text { default }} \\
B_{\mathrm{dec}}=B_{\mathrm{dec}-1}\end{array}$ & $\begin{array}{l}B_{\mathrm{dec}}=B_{\mathrm{dec}-1}\left(Y_{\mathrm{dec}} / Y_{\mathrm{dec}-1}\right) \\
B_{\mathrm{dec}}=B_{\mathrm{dec}-1}\left(Y_{\mathrm{dec}} / Y_{\mathrm{dec}-1}\right)\end{array}$ \\
\hline
\end{tabular}




\section{RESULTS}

Unless otherwise noted, the results presented below are based on an analysis of the biomass predictions under Scenario 2 (intermediate), which assumes that local declines in fisheries catches are due to overexploitation and that the underlying biomass can recover if overexploitation ceases.

\section{Estimates of global biomass}

Predictions of marine global biomass made using the EcoTroph model can be compared with currently available published estimates (Table 3). For the total biomass ('marine animals', or TL $\geq 2$ ), our estimates of unexploited biomass are considerably higher than those of Jennings et al. (2008). Our estimate for predators ( $\mathrm{TL} \geq 3.5$ ) is bracketed between the lower estimate of Jennings et al. (2008) and the higher estimate of Wilson et al. (2009).

\section{General trends in the decline of global marine biomass}

We calculated the ratio (in \% by decade) of fished to unexploited biomass for the world's oceans (Fig. 2, left). The ratio decreases between 1950 and the 2000s, with predator biomass ( $\mathrm{TL} \geq 3.5$ ) declining faster than total biomass ( $\mathrm{TL} \geq 2$ ). Global predator biomass was at approximately $85 \%$ of its unexploited value in the $1950 \mathrm{~s}$, and had declined to approximately $60 \%$ by the 2000 s. Predator decline was further assigned to High Seas and EEZ cells (Fig. 2, center). This showed that the decline of the biomass of predators within EEZs was stronger, with
Table 3. Comparison of published predictions of global ecosystem biomass $\left(\times 10^{9}\right.$ tonnes), including assumption about the exploitation status of ecosystems and the ecosystem subset for which biomass is estimated

\begin{tabular}{|lcrcc|}
\hline $\begin{array}{l}\text { Ecosystem } \\
\text { status }\end{array}$ & Subset & $\begin{array}{c}\text { Present } \\
\text { study }\end{array}$ & $\begin{array}{c}\text { Jennings } \\
\text { et al. (2008) }\end{array}$ & $\begin{array}{c}\text { Wilson } \\
\text { et al. (2009) }\end{array}$ \\
\hline Unexploited & $\mathrm{TL} \geq 2$ & $\begin{array}{r}11.82 \\
1.56\end{array}$ & 2.62 & 0.90 \\
& $\mathrm{TL} \geq 3.5$ & 2.05 \\
In the 2000s & $\mathrm{TL} \geq 2$ & 10.98 & & \\
& $\mathrm{TL} \geq 3.5$ & 1.08 & & \\
& & & & \\
\hline
\end{tabular}

biomass in the 2000s being less than $50 \%$ of its unexploited value. Lastly, predator biomass in EEZs were disaggregated into individual oceans (Fig. 2, right), which showed a latitudinal trend in biomass decline from North to South. The North Atlantic and the North Pacific show the strongest decline overall with the proportion of remaining predator biomass slightly above $20 \%$.

\section{Spatial trends of decline in predator biomass}

The ratio (in \%) of decadal to unexploited predator biomass was mapped from the 1950s to the 2000s (Fig. 3). Zones of high biomass decline (ratio < 40\%) already existed at northern latitudes in the 1950s, especially in European waters but also on the east coast of North America and in Asia. Zones of high decline expanded during the 1960s in these latter areas, and also started to appear in equatorial and tropical waters in the 1970s, most notably in Africa and in southwest Asia. In the subsequent decades, zones of high decline extended to South America and the southern part of the Indian Ocean in the 1970s,
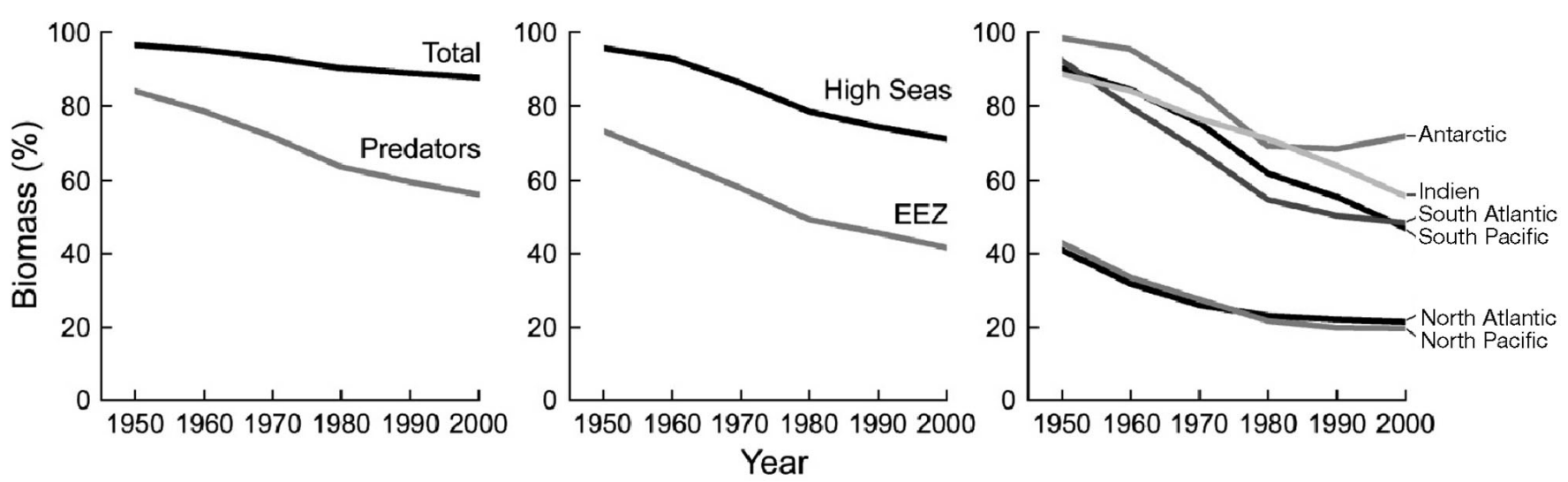

Fig. 2. Global trends in biomass ( $\%$ unexploited biomass). Left: overall (TL $=2-5$ ) and predator biomass (TL $\geq 3.5$ ). Centre: predators in the High Seas and within exclusive economic zones (EEZs). Right: predators within EEZs, by ocean 
and to the High Seas in the 1980s. The spatial extent of high decline zones continues to increase overall in 1990s and 2000s, except in the Antarctic where the decline becomes less important.

In order to quantify the spatial trends in the status of predator decline for the current decade (2000s), we calculated the proportion of each ocean's coastal area (EEZ) in which less than $40 \%$ and less than $10 \%$ of predator biomass remained (Fig. 4). The values of $10 \%$ and $40 \%$ were chosen as an equivalent to the $B_{10}$ and $B_{40}$ values often used as reference points in stock assessments. The North Atlantic and the North Pacific feature the strongest declines in predator biomass, with $66.4 \%$ and $71.4 \%$ of their respective coastal area being below $B_{40}$, and $48.4 \%$ and $48.7 \%$ being below $B_{10}$.

\section{Scenarios of ecosystem response to fishing}

Our scenarios of ecosystem response to fishing resulted in 3 sets of biomass estimates (Fig. 5). Scenario 1 (optimistic) generated the highest biomass, particularly for the High Seas where the decline since the 1950s is predicted to be minimal. Under this optimistic scenario, predators also declined in EEZs over the 50 yr period, with less than $60 \%$ of predator biomass remaining by the 2000s. The predictions made by Scenarios 2 (intermediate) and 3 (pessimistic) are very close and generated strong declines with, in both cases, less than $40 \%$ of the predator biomass remaining in coastal areas.

\section{DISCUSSION}

We estimated the biomass in marine ecosystems worldwide using a model that gives a simple but potentially useful representation of ecosystems. Our estimates of biomass are based on basic principles of energy transfer between TLs and account for primary production, sea surface temperature, fisheries catch and TL of species caught. The focus on TLs is especially appropriate in a fisheries context: high-TL species have historically been under heavier exploitation because of their high market demand and vulnerability to fishing gear, and are also intrinsically more sensitive to the effects of fishing (Dulvy et al. 2003, Cheung et al. 2005).

Our objectives in this study were 2-fold. First we aimed to further the understanding of the flow of energy in marine ecosystems through the broadscale application of EcoTroph. In addition, this study contributes to the ongoing debate in the literature about the sustainability of global fisheries (Pauly et al. 1998, Pauly et al. 2002, Worm et al. 2009, Branch et al. 2010). Today's applied scientists are faced with the dilemma that simple metrics often have shortcomings yet are the most efficient at conveying information to policy makers and the public. Although we acknowledge that our predictions of biomass are likely inaccurate in some locations because they come from a simple ecosystem model, this study nonetheless proves to be useful by its efficient illustration of qualitative spatial trends in the worldwide extraction of marine production.

\section{Global marine biomass estimates: assumptions and scenarios}

EcoTroph generates estimates of unexploited marine biomass by TL based on estimates of primary production and a measure of the transfer efficiency (TE) of energy (or biomass) between TLs, here set at $10 \%$. This approach resulted in an estimated unexploited biomass of $11.82 \times 10^{9}$ tonnes for TLs $\geq 2$ (i.e. including zooplankton), and $1.56 \times 10^{9}$ tonnes for predators ( $T L \geq 3.5$ ). These estimates are sensitive to the value of $T E$, with estimates of biomass (especially at high TL) declining rapidly with the value of $T E$ (see supplement).

These results can be compared with those of a few studies that have likewise attempted to estimate worldwide unexploited biomass for either the whole or a subset of marine ecosystems (Table 3). Jennings et al. (2008) used size-spectrum theory to estimate a global biomass of 'marine animals' of $2.62 \times 10^{9}$ tonnes. Assuming that 'marine animals' are equivalent to the biomass at $\mathrm{TL} \geq 2$, their estimate is less than a quarter of ours. Jennings et al. (2008)'s model appears to be very sensitive to $T E$ and to a parameter called the 'predator-prey mass ratio'. Qualitatively though, the spatial trends in the repartition of global 'marine animals' biomass are similar between their study and ours (see Tremblay-Boyer 2010). With regards to higher-TL organisms, Jennings et al. (2008)'s estimate for 'teleost biomass' is $0.90 \times 10^{9}$ tonnes, whereas a study by Wilson et al. (2009) estimated the biomass of finfishes to be $2.05 \times 10^{9}$ tonnes from a global complex of Ecopath models (Christensen \& Pauly 1992). Because EcoTroph does not make taxonomic distinctions, we cannot isolate the teleost component from our biomass estimate. However, we can note that our estimate of biomass $1.56 \times 10^{9}$ for TL $\geq 3.5$ lies between the estimates of the 2 aforementioned 

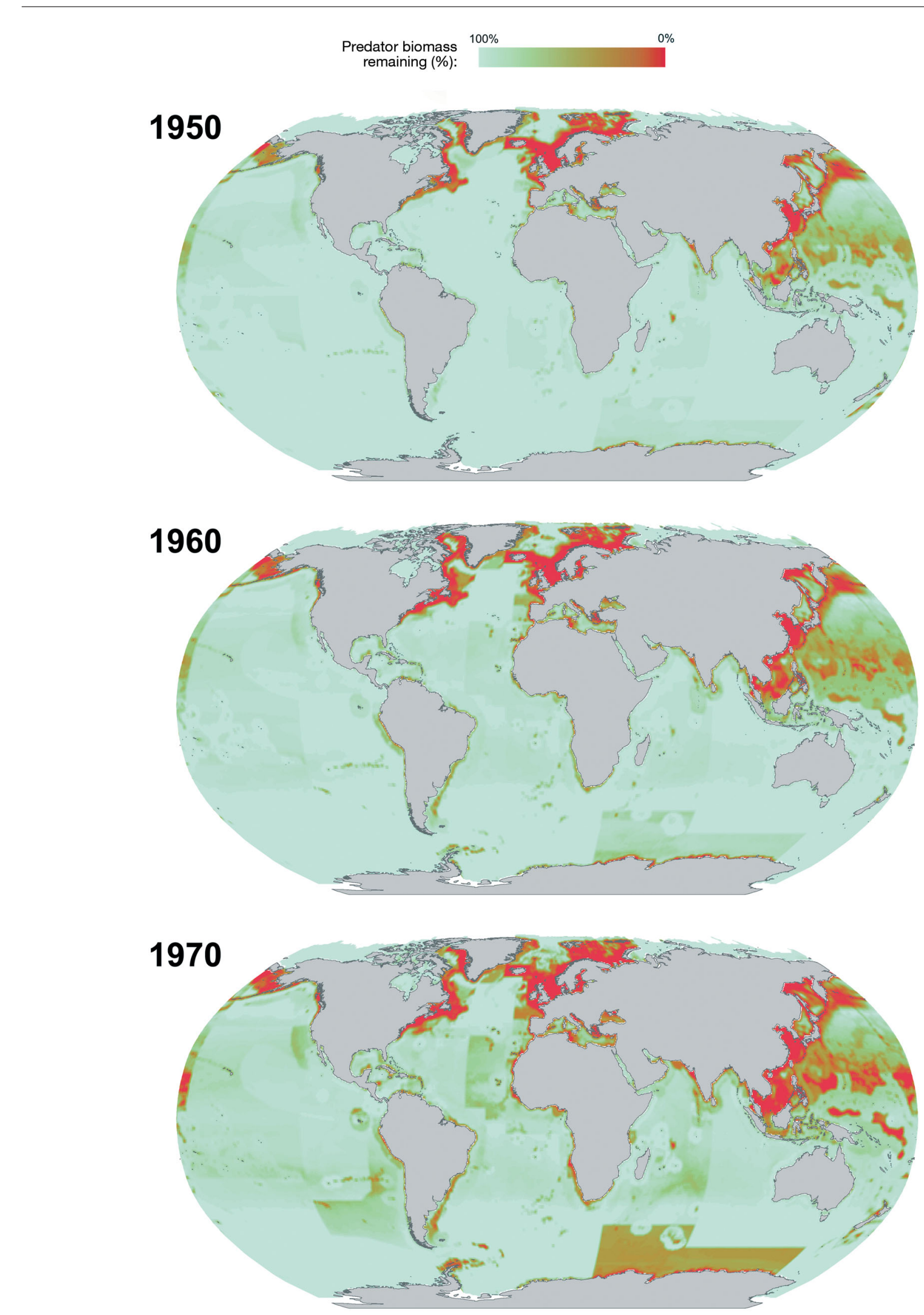

Fig. 3. Proportion of predator biomass (TL $\geq 3.5$ ) remaining after each successive decade of fishing (1950s to 2000s) under Scenario 2 (intermediate). Sharp boundaries are indicative of the limits of major areas which the Food and Agriculture Organization of the United Nations (FAO) uses to report fisheries statistics (upon which most of the spatialized catches used here are based). Biomass decline was not modelled for cells in white (see 'Methods') 

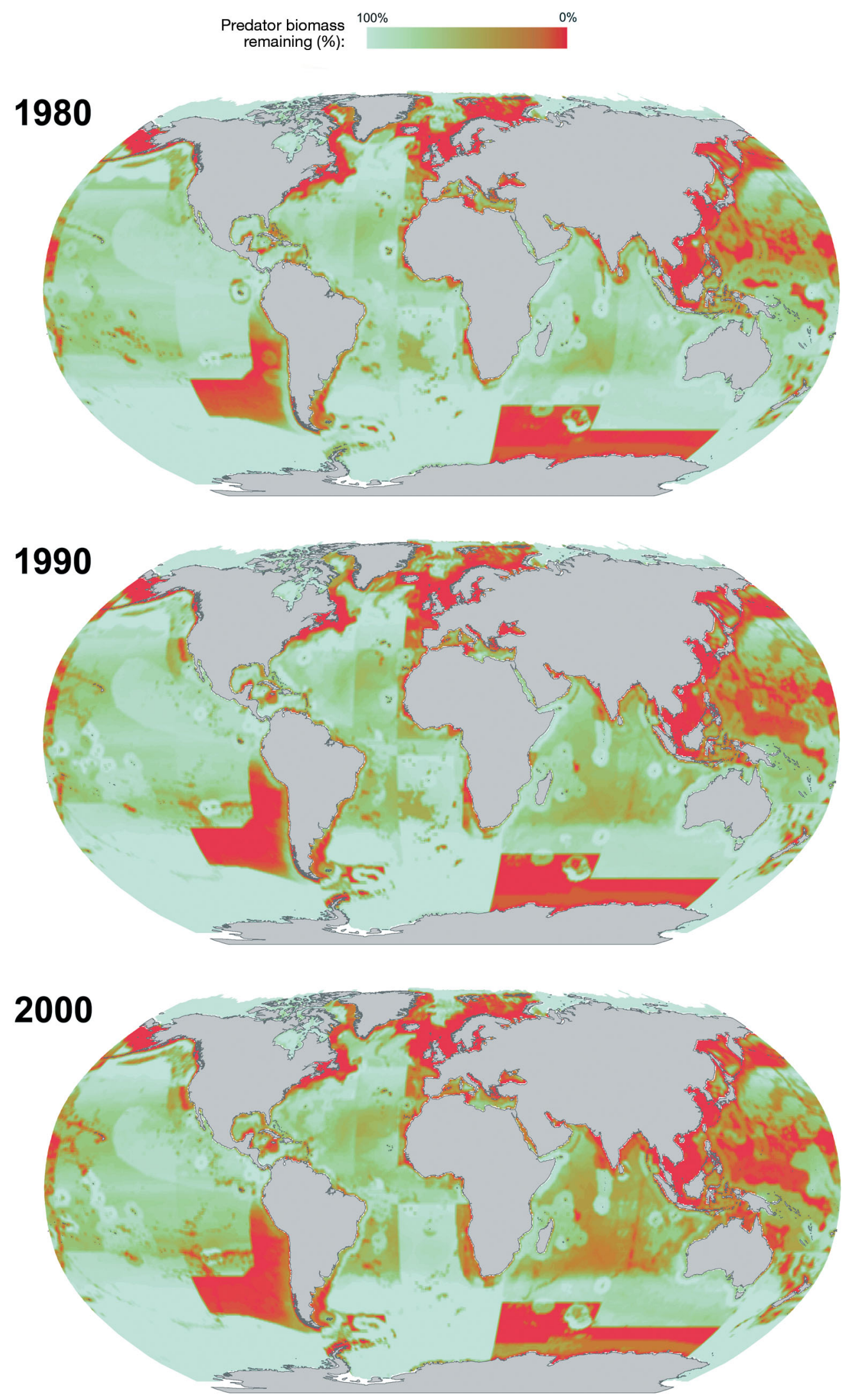

Fig. 3 (continued) 


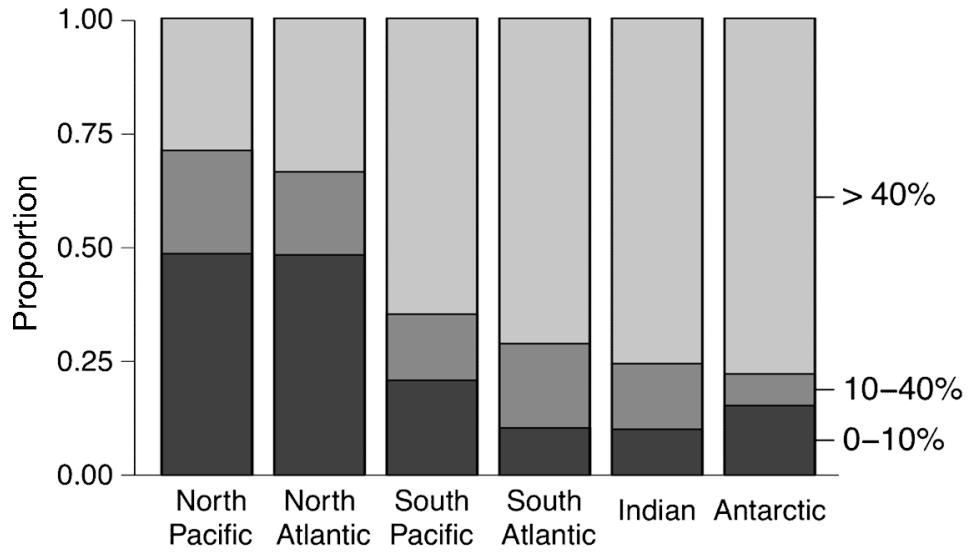

Fig. 4. Proportion of the coastal (exclusive economic zone, EEZ) area of each ocean with $0-10 \%$ (dark grey), 10-40\% (grey) and $>40 \%$ (light grey) of predator biomass left under the intermediate scenario

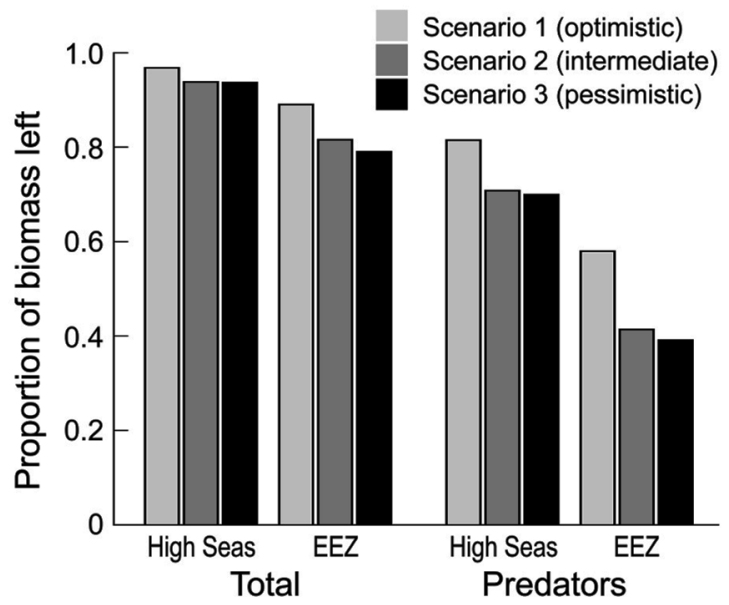

Fig. 5. Biomass left in the 2000s as fraction of unexploited biomass for the 3 different scenarios applied to EcoTroph outputs. The percentage biomass remaining is calculated for total ( $\mathrm{TL} \geq 2$ ) and predator biomass ( $\mathrm{TL} \geq 3.5$ ), and disaggregated into High Seas and coastal areas (exclusive economic zones, EEZs)

studies ${ }^{\mathbf{1}}$. Estimates generated through EcoTroph and Ecopath are both higher than that of Jennings et al. (2008), which could be due to a fundamental similarity in their logic (Gascuel et al. 2009) and their use of similar catch data. We note, however, that the global biomass of mesopelagic fishes alone, based on survey information, has been roughly estimated to be approximately $1 \times 10^{9}$ tonnes (Lam \& Pauly 2005, based on Gjøsaeter \& Kawaguchi 1980), which could indicate that the global biomass estimate of Jennings et al. (2008) is too low.

${ }^{1}$ Note that our estimates for 'teleosts' (derived from teleosts $=\mathrm{TL} \geq 3.5$ ) would decrease if we excluded non-teleosts (marine mammals, rays and skates, squids, etc.), but increase if we included bony fishes with $\mathrm{TL} \leq 3.5$; these 2 effects may compensate for each other, at least partly
Estimated biomass for the world's oceans under the ecosystem response to fishing implied by Scenario 1 (optimistic) was, in the $2000 \mathrm{~s}, 10.98 \times 10^{9}$ tonnes for $\mathrm{TL} \geq 2$ and $1.08 \times$ $10^{9}$ tonnes for $\mathrm{TL} \geq 3.5$. These correspond to declines from unexploited biomass of $7.1 \%$ and $30.8 \%$, respectively. These values, however, must be interpreted in their proper context. First, approximately one-third of ecosystem biomass (excluding phytoplankton) has a TL $\leq$ 2.3 and mostly consists of zooplankton, which are, with the exception of some Antarctic krill, not targeted by fishing. Second, our catch data are incomplete; thus, the catch from 'illegal, unreported and unregulated' (IUU) fisheries were not included in the analysis, despite comprising up to $140 \%$ of the reported catch in some regions (Agnew et al. 2009, see also Zeller \& Pauly 2005 on discards). Lastly, Scenario 1 is simply too optimistic in assuming that declines in fisheries catches are due exclusively to a reduction in fishing mortality and that biomass recovers fully as soon as fishing stops.

To address this latter concern, we estimated global marine biomass under 2 additional scenarios of ecosystem response to fishing (Fig. 5). The optimistic scenario predicts as expected the smallest reduction of ecosystem biomass due to fishing, but the main trends are conserved: depletion is strongest for predators and along coastlines. Scenarios 2 and 3 yielded very similar predictions of biomass, especially for the High Seas (Fig. 5). This was expected because the only difference in these scenarios is the fate of the biomass when a given TL interval recovers from overexploitation (see 'Methods' and supplement), and most recorded stock recoveries occurred for low-TL species (Hutchings 2000), which are mainly coastal. Even then, the largest difference between Scenarios 2 and 3 (the predicted proportion of biomass left in 2000 for predators within EEZs) was only $2.6 \%$ (Fig. 5). This tells us that few predators have recovered (according to our criteria) after having been overexploited.

Note that our label of 'pessimistic' for Scenario 3 could be questioned. Recall that in this scenario decreases in catch are assumed to result from a decline in biomass, with fishing mortality remaining constant. However, it is well established from single-species population dynamic models that overexploitation is characterized by increasing fishing mortalities and decreasing catch and biomass (see for example Walters \& Maguire 1996). Thus, assuming constant fishing mortalities, as we do in our 'pes- 
simistic' Scenario 3, may still be too optimistic and could underestimate the decline in the ecosystem biomass.

A data set of fishing mortality and/or effort could have been used to explain whether declining catches were caused by reduced effort or overexploitation. However, although there is now a global database of standardized fishing effort (Anticamara et al. 2011), it has not yet been spatialized such that it could be superimposed on our grid. Even if we had access to such data, simple fisheries-dependent catch per unit effort time-series are often not a reliable indicator of abundance (Walters \& Martell 2004). An alternative would have been to directly include a relationship in the model to describe the ecosystem response to fishing, such that, for example, the biomass associated to a declining catch in 2000 would have been a function of historical catches. However, such a relationship implies the need to define ecosystem resilience to fishing as a function of TL, possibly accounting for local abiotic and biotic factors. Describing such a relationship is not straightforward; indeed, the question of single-species resilience to fishing is still one of the most challenging in fisheries science and it is unclear how population-specific principles of recruitment feedback scale up at the ecosystem level. For example, it could be that ecosystems become more productive when fished because populations are made of smaller individuals with faster turnover (Denney et al. 2002). In contrast, the transfer of energy to higher TLs could be hindered by the appearance of 'trophic culs-de-sac' (Bishop et al. $2007)$, i.e. the proliferation of lower-trophic groups that have few higher-TL predators such as jellyfish (Pauly et al. 2009, Richardson et al. 2009).

Instead of adding an extra layer of complexity to our model, we opted to maintain its simple structure and adjust the estimates of biomass it generated by using a set of straightforward rules corresponding to our 3 different scenarios. Still, the rules underlying our scenarios could be fine-tuned; for instance, the recovery function of Scenario 2 could be parameterized using a relationship linking the intrinsic rates of increase of organism to their body mass (Blueweiss et al. 1978) and hence their TL.

\section{Spatial and temporal trends in how fishing impacts ecosystem biomass}

Our model's results are in line with the trends documented in the literature of the last 2 decades. Fishing impact, expressed here as a reduction in biomass by $\mathrm{TL}$, is much stronger for predators and along coasts (i.e. within EEZs) (Fig. 2). Fishing impact was already strong in the 1950s in the North Atlantic and in the Southern East China Sea, with a number of cells showing aa predator decline of $60 \%$ or more (Fig. 3), or below the $B_{40}$ threshold often used as a reference in single-species stock assessment. The initial high impact in both the North Atlantic and North Pacific is expected from the history of industrial fisheries (Lotze 2007, Roberts 2007) and has been reported by other authors, e.g. for the North Atlantic (Christensen et al. 2003b, Thurstan \& Roberts 2010), Southeast Asia (Christensen et al. 2003a) and Northwest Africa (Christensen et al. 2004, Gascuel et al. 2007). Areas of high impact continued to increase throughout the 1960s and 1970s and showed a gradual spread towards low latitudes (Northwestern Africa, Southeast Asia) and the Southern Hemisphere (Southwest Africa, South America, Antarctica) (Figs. 2 and 3). This gradual transition in impact from northern to southern waters is likely the result of increased exploitation of tropical waters by distant water fleets of northern countries starting in the 1960s, which has been shown by authors working from both an economics (Alder \& Sumaila 2004, Swartz et al. 2010) and a marine ecology (Coll et al. 2008) standpoint. Except for the Antarctic, biomass declined at about the same rate in the Northern and Southern Hemispheres, though with a delay in the latter. Both the North Atlantic and the North Pacific showed a fast decline of predator biomass in coastal areas up to the 1970 s, with a leveling at approximately $20 \%$ of the unexploited biomass in the last 2 decades (Fig. 2, right). The High Seas near China and Japan were affected as early as the 1950 s, with pockets of high biomass depletion appearing throughout the world in the 1980s (Fig. 3). The 2000s show an accentuation of existing trends, especially in terms of impact on the High Seas (Fig. 3). Our model predicts a relatively low fishing impact in the High Seas compared with the coasts, with almost no High Seas cells experiencing predator biomass decline in excess of $40 \%$ of unexploited biomass (Fig. 3). This was expected given the high costs and technological challenges of fishing far offshore, and because we presently do not exploit mesopelagic fishes (TL $=3.0$ to 3.4) (e.g. Valinassab et al. 2007).

Our results consistently show that the effects of fishing are greater on predators than on lower TLs (Fig. 2, left, and Fig. 5). This is not surprising given the difference between catches and biomass in the upper TLs of ecosystems. Animals with TL $\geq 3.5$ contribute approximately $40 \%$ of global catches since 
the 1950 s, while making up only $13 \%$ of the total biomass of marine ecosystems in the current parameterization of our model. High TLs are also intrinsically more sensitive to fishing pressure because of a turnover of biomass that is, on average, lower compared with intermediate or low TLs (Gascuel et al. 2008, Gascuel \& Pauly 2009). The biomass of predators in EcoTroph is also negatively impacted by the loss of food source when their prey is being fished. In the past $10 \mathrm{yr}$, a number of studies have reported strong decline in the global abundance of marine predators, primarily from time-series of biomass proxies (see, e.g. Myers \& Worm 2003). Our modelling approach adds an independent confirmation to these observations. Lastly, our estimates of average predator decline are likely to be conservative owing to our assumption that biomass is at unexploited levels before the 1950s. For example, in the North Atlantic, we predict a decline of $80.3 \%$ (Fig. 2, right), whereas Christensen et al. (2003b) and Thurstan \& Roberts (2010) have documented declines of $90 \%$ and more for essentially the same groups as covered here.

We presented declines aggregated over large regions (e.g. the smallest region, the North Atlantic outside of EEZs, has an area of 23.7 million $\mathrm{km}^{2}$ ), which failed to capture the heterogeneity of the decline between individual cells. To compensate for this, we showed the proportion of the area of exploited coastal cells in which given proportions of predator biomass $(10 \%$ and $40 \%)$ remain in 2000 (Fig. 4). Unsurprisingly, coastal cells in waters of the South Hemisphere have, on average, more predator biomass left, but still show some biomass decline. The Indian, South Atlantic and South Pacific Oceans have between one-fourth and one-third of their area with less than $40 \%$ of the predator biomass left and, in all 3 cases, at least $10 \%$ of their area already shows a decline of more than $90 \%$ of predator biomass despite the relatively recent arrival of industrial fisheries in those waters. The potentially high global impact of fisheries can be seen by looking at the North Atlantic and North Pacific Oceans, which have historically been heavily exploited over the 1950 to 2006 period. For both oceans, approximately $50 \%$ of their coastal areas (48.4\% and $48.7 \%$, respectively) have less than $10 \%$ of the original predator biomass left. We note that these values compare with other studies that have estimated declines of more than $90 \%$ in predator biomass (Pauly et al. 1998, Myers \& Worm 2003, but see Walters 2003) and that local field studies have also shown similar results. Friedlander \& DeMartini (2002), for example, surveyed fish biomass (including some TLs > 3.5) in North Hawaii under heavily and lightly fished conditions and found a decline of biomass of approximately $61.5 \%$, with the decline stronger for large apex predators. Studies in the field of historical ecology also corroborate our results with, for instance, large sharks and other trophy fish shown to have declined significantly in the Florida Keys since the 1950s (McClenachan 2009) and the relative abundance of species guilds corresponding to marine predators (except for pinnipeds and otters) declining to below $40 \%$ compared with prehistorical status for 12 important coastal and estuarine ecosystems (Lotze et al. 2006).

Lastly, there are some local instances where we know that the EcoTroph model does not adequately predict changes in biomass. For the Mediterranean, the impacts seem low given the history of exploitation and the current state of the ecosystem. However, recorded catches for predators with $\mathrm{TL} \geq 3.5$ have been relatively limited compared with the available production since the 1950s, possibly because some of the migratory species (e.g. bluefin tuna) are recorded as being caught elsewhere, or because the predator biomass had already been driven low by the 1950s, or because of the prevalence of IUUs in the Mediterranean (Swan 2005). Our model assumes that the biomass before the 1950s was at the unexploited level and therefore does not give an accurate depiction of the current state of this historically exploited ecosystem. There are also well documented issues of overestimation of primary production in the Mediterranean from the SeaWifs satellite data (see section 3.3 in Gregg \& Casey 2004), which would result in a negative bias in the estimates of biomass decline. The Bering Sea is another instance for which we predict an important drop in the biomass of predators, whereas observations show that ecosystem biomass has stayed roughly constant despite important shifts in species abundance (National Research Council 1996). We see such disagreements between model and observations as an opportunity to further our understanding of local ecosystem functioning. We averaged the results presented in this study over very large regions (for example, the East Bering Sea Large Marine Ecosystem makes up less than 5\% of the North Pacific) to minimize the overall impacts of such discrepancies on the overall trends.

\section{Key assumptions and caveats of EcoTroph}

In this study, the impacts of fishing on ecosystem biomass are driven by direct catch whereas fishing affects ecosystems in other ways such as habitat dis- 
turbance (Watling \& Norse 1998) and indirect ecological effects like trophic cascades (Scheffer et al. 2005). It is therefore important to acknowledge that our results focus on a subset of the possible ecosystem impacts of fishing. Moreover, as expected, the accuracy of EcoTroph's predictions is driven by the quality of the input data (most notably the catch), the validity of the parameters used and the model formulation.

The most sensitive parameter in EcoTroph is $T E$, that is, the proportion of production that is retained in transfers between TLs. Our sensitivity analysis showed that TE had a high impact on both the predicted biomass of an ecosystem and the resulting proportion of biomass removed from fishing (see supplement). As TE becomes smaller, the biomass that can be supported at higher TLs decreases and so the observed impacts of fishing are greater. However, the relative spatial trends are not affected much by the specific value of $T E$, i.e. the impact of fishing on one cell compared with the next remains the same. In terms of our objectives of extracting general spatial and temporal trends, our results are therefore robust to the uncertainty in TE. This would not necessarily be the case if, as we should expect, $T E$ varies between regions; in such instances, the biomass of systems with higher $T E$ would have been underestimated and the biomass of systems with lower TE overestimated, which would affect the relative patterns of biomass decline. There is currently no consensus on trends in TE between systems, which is why we used the same constant value for all systems (but see Christensen \& Pauly 1993). However, the 2 systems for which we know that TE departs from the mean, coral reefs and upwelling zones (Christensen \& Pauly 1993), form only a small proportion of the areas over which we aggregated our results. Knowledge of the biotic or physical factors that drive TE over the world's oceans would be an important step towards a better understanding of marine ecosystem functioning.

The EcoTroph model is a very simple representation of ecosystems, which allowed us to extract general trends of marine ecosystem structure and function at the global scale. Its underlying assumption is that only processes of predation determine biomass at any TL (i.e. bottom-up and/or top-down effects). In terrestrial systems, it has been shown that production at any TL could be strongly affected by community composition, and that competition between species has a strong effect on ecosystem properties (Tilman et al. 1997). Whether such processes are as important in marine systems is unclear, but a positive correla- tion has been observed between prey energy content and trophic TE (e.g. Atkinson et al. 2004). Also, the current version of EcoTroph assumes that parameters such as TE are constant over time and thus are not affected by fishing induced changes in the species composition of communities.

We were unable to assign a robust value for the top-down effect that covered the world's marine ecosystems and decided not to include the effect in the analysis. There is no consensus about the drivers behind top-down effects and how they change between systems (see Borer et al. 2005, Gruner et al. 2008, Frank et al. 2007, Shurin et al. 2002), but it is clear to the scientific community that they can play an extremely important role in ecosystem structure. An interesting future direction to this work would be to investigate how different hypotheses about the factors that influence the strength of top-down effects would affect the predicted spatial, temporal and trophic trends about the effects of fishing.

Finally, the current formulation of the model does not account for recruitment feedback; thus, even if the biomass of a given TL interval is completely depleted by the catch in a given year, it will be regenerated the following year by a new pulse of production. In this study we used scenarios to compensate for this unrealistic behavior. An improved formulation of the model could define a relationship between biomass and future recruitment as a function of TL, with the assumption that past biomass has a stronger effect on future recruitment as TL increases.

\section{Conclusions}

By using a modelling approach, our study outlined and confirmed 3 main trends about the impact of global fishing on ecosystems: the impacts are considerably greater for predators, are concentrated in coastal areas and have gradually expanded from northern to equatorial and southern waters. We showed that the long-term operations of fisheries have severely reduced the biomass of predators in their historical fishing grounds, and that this trend is spreading rapidly to areas developed more recently.

The advantages of using EcoTroph to model marine ecosystems globally are 2-fold. First, by focusing on TLs and processes of energy transfer, it gives a general overview of ecosystem structure and function. Second, EcoTroph is well suited to data-poor situations and can generate biomass estimates from the data sets that are currently available globally. Its pre- 
dictions can be easily compared with those of other ecosystem models or field data by aggregating species by TL. There are many additional factors that would have been relevant to include in this assessment of the impacts of global fisheries. For instance, it would be interesting to account for top-down effects in the EcoTroph model as these have been demonstrated to occur in many fished ecosystems. However, it is important to emphasize that this is a first attempt at the application of a model to estimate trends in marine biomass under fishing at the global scale.

To conclude, in the last decade many studies have reported the effects of fishing at multiple scales, through field studies, metrics, models and the analysis of time-series. The one trend consistently observed is that fishing truncates a considerable portion of the biomass pyramid of ecosystems. Although the current global modelling approach focused on the effects of fishing only from the standpoint of direct biomass removal, the prediction of generalized predator decline implies widespread and fundamental changes to both the structure and the functioning of global marine communities.

Acknowledgements. We thank Dr. Maria-Lourdes 'Deng' Palomares and Ms Grace Pablico for valuable assistance with TLs from FishBase and SeaLifeBase as well as 2 anonymous reviewers for their helpful feedback on the manuscript. Funding for L.T.-B. was provided by an Alexander Bell Canadian Graduate Scholarship from NSERC and a scholarship through the French General Consulate in Vancouver. This work was performed as part of the Sea Around Us Project, a scientific collaboration between the University of British Columbia and the Pew Environmental Group.

\section{LITERATURE CITED}

Agnew DJ, Pearce J, Pramod G, Peatman T, Watson R, Beddington JR, Pitcher TJ (2009) Estimating the worldwide extent of illegal fishing. PLoS ONE 4:e4570

Alder J, Sumaila UR (2004) Western Africa: a fish basket of Europe past and present. J Environ Dev 13:156

> Anticamara JA, Watson R, Gelchu A, Pauly D (2011) Global fishing effort (1950-2010): trends, gaps, and implications. Fish Res 107:131-136

Atkinson A, Siegel V, Pakhomov E, Rothery P (2004) Longterm decline in krill stock and increase in salps within the Southern Ocean. Nature 432:100-103

Baum JK, Worm B (2009) Cascading top-down effects of changing oceanic predator abundances. J Anim Ecol 78: 699-714

> Berkes F, Hughes TP, Steneck RS, Wilson JA and others (2006) Globalization, roving bandits, and marine resources. Science 311:1557-1558

Bishop MJ, Kelaher BP, Alquezar R, York PH, Ralph PJ, Skilbeck CG (2007) Trophic cul-de-sac, Pyrazus ebeninus, limits trophic transfer through an estuarine detritus- based food web. Oikos 116:427-438

Blueweiss L, Fox H, Kudzma V, Nakashima D, Peters R, Sams S (1978) Relationships between body size and some life-history parameters. Oecologia 37:257-272

> Borer E, Seabloom E, Shurin J, Anderson K and others (2005) What determines the strength of a trophic cascade? Ecology 86:528-537

Bouvet M, Hoepffner N, Dowell MD (2002) Parameterization of a spectral solar irradiance model for the global ocean using multiple satellite sensors. J Geophys Res 107:3215

Branch TA, Watson R, Fulton EA, Jennings S and others (2010) The trophic fingerprint of marine fisheries. Nature 468:431-435

Casini M, Lovgren J, Hjelm J, Cardinale M, Molinero J, Kornilovs G (2008) Multi-level trophic cascades in a heavily exploited open marine ecosystem. Proc R Soc Lond B 275:1793-1801

CBD (Convention on Biological Diversity) (2008) Ecosystem approach. Available at www.cbd.int/ecosystem/

Cheung WWL, Pitcher TJ, Pauly D (2005) A fuzzy logic expert system to estimate intrinsic extinction vulnerabilities of marine fishes to fishing. Biol Conserv 124:97-111

Christensen V, Pauly P (1992) The ECOPATH II - a software for balancing steady-state ecosystem models and calculating network characteristics. Ecol Model 61:169-185

Christensen V, Pauly D (1993) Flow characteristics of aquatic ecosystems. In: Christensen V, Pauly D (eds) Trophic models of aquatic ecosystems. ICLARM, Manila

Christensen V, Garces L, Silvestre GT, Pauly D (2003a) Fisheries impact on the South China Sea Large Marine Ecosystem: a preliminary analysis using spatially explicit methodology. In: Munro P, Christensen V, Pauly D (eds) Assessment, Management and Future Directions for Coastal Fisheries in Asian Countries, Book 67. WorldFish Center, Penang

Christensen V, Guenette S, Heymans JJ, Walters CJ, Watson R, Zeller D, Pauly D (2003b) Hundred-year decline of North Atlantic predatory fishes. Fish Fish 4:1-24

Christensen V, Amorim P, Diallo I, Diouf T and others (2004) Trends in fish biomass off Northwest Africa, 1960-2000. In: Chavance P, Ba M, Gascuel D, Vakily M, Pauly D (eds) Actes du symposium international, Book XXXVI collection des rapports de recherche halieutique ACPUE 15. Office des publications officielles des communautés Européennes, Dakar

Coll M, Libralato S, Tudela S, Palomera I, Pranovi F (2008) Ecosystem overfishing in the ocean. PLoS ONE 3:e3881

> Denney NH, Jennings S, Reynolds JD (2002) Life-history correlates of maximum population growth rates in marine fishes. Proc R Soc Lond B 269:2229-2237

Dulvy NK, Sadovy Y, Reynolds JD (2003) Extinction vulnerability in marine populations. Fish Fish 4:25-64

FAO (2009) The State of World Fisheries and Aquaculture (SOFIA) 2008. FAO Fisheries and Aquaculture Department, Rome

- Frank KT, Petrie B, Choi J, Leggett W (2005) Trophic cascades in a formerly cod-dominated ecosystem. Science 308:1621-1623

Frank KT, Petrie B, Shackell N (2007) The ups and downs of trophic control in continental shelf ecosystems. Trends Ecol Evol 22:236-242

Friedlander AM, DeMartini EE (2002) Contrasts in density, size, and biomass of reef fishes between the northwestern and the main Hawaiian islands: the effects of fishing down apex predators. Mar Ecol Prog Ser 230:253-264 
Fulton EA, Smith ADM, Johnson CR (2003) Effect of complexity on marine ecosystem models. Mar Ecol Prog Ser 253:1-16

Gascuel D (2005) The trophic-level based model: a theoretical approach of fishing effects on marine ecosystems. Ecol Model 189:315-332

Gascuel D, Pauly D (2009) EcoTroph: Modelling marine ecosystem functioning and impact of fishing. Ecol Model 220:2885-2898

Gascuel D, Labrosse P, Meissa B, Sidl MOT, Guenette S (2007) Decline of demersal resources in North-West Africa: an analysis of Mauritanian trawl-survey data over the past 25 years. Afr J Mar Sci 29:331-345

Gascuel D, Morissette L, Palomares MLD, Christensen V (2008) Trophic flow kinetics in marine ecosystems: toward a theoretical approach to ecosystem functioning. Ecol Model 217:33-47

Gascuel D, Tremblay-Boyer L, Pauly D (2009) EcoTroph (ET): a trophic level based software for assessing the impacts of fishing on aquatic ecosystems. Fish Cent Res Rep 17:1-82

Gjøsaeter J, Kawaguchi K (1980) A review of the world resources of mesopelagic fish. In: FAO Fisheries Technical Paper No 193, Book 193. FAO, Rome

Gregg WW, Casey NW (2004) Global and regional evaluation of the SeaWiFS chlorophyll data set. Remote Sens Environ 93:463-479

> Gregg WW, Ginoux P, Schopf PS, Casey NW (2003) Phytoplankton and iron: validation of a global threedimensional ocean biogeochemical model. Deep-Sea Res II 50:3143-3169

> Gruner DS, Smith J, Seabloom E, Sandin S and others (2008) A cross-system synthesis of consumer and nutrient resource control on producer biomass. Ecol Lett 11: 740-755

Hilborn R (2007) Managing fisheries is managing people: What has been learned? Fish Fish 8:285-296

Hutchings JA (2000) Collapse and recovery of marine fishes. Nature 406:882-885

> Jackson JBC (2001) What was natural in the coastal oceans? Proc Nat Acad Sci USA 98:5411-5418

> Jennings S, Melin F, Blanchard JL, Forster RM, Dulvy NK, Wilson RW (2008) Global-scale predictions of community and ecosystem properties from simple ecological theory. Proc R Soc Lond B 275:1375-1383

Lai S (2004) Primary production methodology. Fisheries Centre, Univeristy of British Columbia, Vancouver, available at www.seaaroundus.org/primaryproduction/interpolation_method.htm

Lam V, Pauly D (2005) Mapping the global biomass of mesopelagic fishes. Sea Around Us Project Newsl July/August 30:4

> Lotze HK (2007) Rise and fall of fishing and marine resource use in the Wadden Sea, southern North Sea. Fish Res $87: 208-218$

Lotze HK, Worm B (2009) Historical baselines for large marine animals. Trends Ecol Evol 24:254-262

> Lotze HK, Lenihan HS, Bourque BJ, Bradbury RH and others (2006) Depletion, degradation and recovery potential of estuaries and coastal seas. Science 312:1806-1809

McClenachan L (2009) Documenting loss of large trophy fish from the Florida Keys with historical photographs. Conserv Biol 23:636-643

McLeod KL, Lubchenco J, Palumbi SR, Rosenberg AA (2005) Scientific consensus statement on marine ecosys- tem-based management. Communication Partnership for Science and the Sea, www.compassonline.org/sites/all/ files/document_files/EBM_Consensus_Statement_v12.pdf

Mullon C, Freon P, Cury P (2005) The dynamics of collapse in world fisheries. Fish Fish 6:111-120

Myers RA, Worm B (2003) Rapid worldwide depletion of predatory fish communities. Nature 423:280-283

National Research Council (1996) The Bering Sea ecosystem: Report of the Committee on the Bering Sea Ecosystem. The National Academies Press, Washington, DC

Pauly D (2007) The Sea Around Us Project: documenting and communicating global fisheries impacts on marine ecosystems. Ambio 36:290-295

Pauly D, Christensen V (1995) Primary production required to sustain global fisheries. Nature 374:255-257

Pauly D, Christensen V, Dalsgaard J, Froese R, Torres F (1998) Fishing down marine food webs. Science 279: 860-863

Pauly D, Christensen V, Guenette S, Pitcher TJ and others (2002) Towards sustainability in world fisheries. Nature 418:689-695

Pauly D, Graham W, Libralato S, Morissette L, Palomares MLD (2009) Jellyfish in ecosystems, online databases, and ecosystem models. Hydrobiologia 616:67-85

Plagányi É (2007) Models for an ecosystem approach to fisheries. In: FAO Fisheries Technical Paper No. 477. FAO Fisheries and Aquaculture Department, Rome

> Platt T, Sathyendranath S (1988) Oceanic primary production: estimation by remote-sensing at local and regional scales. Science 241:1613-1620

> Richardson AJ, Bakun A, Hays GC, Gibbons MJ (2009) The jellyfish joyride: causes, consequences and management responses to a more gelatinous future. Trends Ecol Evol $24: 312-322$

Roberts C (2007) The unnatural history of the sea. Island Press, Washington, DC

> Scheffer M, Carpenter S, de Young B (2005) Cascading effects of overfishing marine systems. Trends Ecol Evol 20:579-581

Shurin JB, Borer ET, Seabloom EW, Anderson K and others (2002) A cross-ecosystem comparison of the strength of trophic cascades. Ecol Lett 5:785-791

Swan J (2005) Implementation of the International Plan of Action to prevent, deter and eliminate illegal, unreported and unregulated fishing: relationship to, and potential effects on, fisheries management in the Mediterranean. FAO Studies and Reviews No. 76. FAO Fisheries and Aquaculture Department, Rome

Swartz W, Sala E, Tracey S, Watson R, Pauly D (2010) The spatial expansion and ecological footprint of fisheries (1950 to present). PLoS ONE 5:e15143

Thurstan RH, Roberts CM (2010) Ecological meltdown in the Firth of Clyde, Scotland: two centuries of change in a coastal marine ecosystem. PLoS ONE 5:e11767

> Tilman D, Knops J, Wedin D, Reich P, Ritchie M, Siemann E (1997) The influence of functional diversity and composition on ecosystem processes. Science 277:1300-1302

Tremblay-Boyer L (2010) Effects of global fisheries on the biomass of marine ecosystems: a trophic-level-based approach. MS thesis, University of British Columbia, Vancouver

Valinassab T, Pierce GJ, Johannesson K (2007) Lantern fish (Benthosema pterotum) resources as a target for commercial exploitation in the Oman Sea. J Appl Ichthyol 23:573-577 
Walters CJ (2003) Folly and fantasy in the analysis of spatial catch rate data. Can J Fish Aquat Sci 60:1433-1436

Walters C, Maguire JJ (1996) Lessons for stock assessment from the northern cod collapse. Rev Fish Biol Fish 6: 125-137

Walters CJ, Martell SJD (2004) Fisheries ecology and management. Princeton University Press, Princeton, NJ

- Walters CJ, Christensen V, Pauly D (1997) Structuring dynamic models of exploited ecosystems from trophic mass-balance assessments. Rev Fish Biol Fish 7:139-172

Watling L, Norse EA (1998) Disturbance of the seabed by mobile fishing gear: a comparison to forest clearcutting. Conserv Biol 12:1180-1197

Watson R, Pauly D (2001) Systematic distortions in world fisheries catch trends. Nature 414:534-536

Watson R, Kitchingman A, Gelchu A, Pauly D (2004) Map-

Editorial responsibility: Konstantinos Stergiou, Thessaloniki, Greece ping global fisheries: sharpening our focus. Fish Fish 5: 168-177

Wilson RW, Millero FJ, Taylor JR, Walsh PJ, Christensen V, Jennings S, Grosell M (2009) Contribution of fish to the marine inorganic carbon cycle. Science 323:359-362

Worm B, Hilborn R, Baum JK, Branch TA and others (2009) Rebuilding global fisheries. Science 325:578-585

Zeller D, Pauly D (2005) Good news, bad news: global fisheries discards are declining, but so are total catches. Fish Fish 6:156-159

Zeller D, Booth S, Davis G, Pauly D (2007) Re-estimation of small-scale for US flag-associated islands in the western Pacific: the last 50 years. Fish Bull 105:266-277

Zeller D, Booth S, Pakhomov E, Swartz W, Pauly D (2011) Arctic fisheries catches in Russia, USA, and Canada: baselines for neglected ecosystems. Polar Biol 34:955-973

Submitted: April 27, 2011; Accepted: August 30, 2011

Proofs received from author(s): November 10, 2011 